\title{
Analysis of Conversational Interaction in the Listening Discourse of Test for English Majors-8
}

\author{
Ziyue Tang \\ Chongqing Normal University, Chongqing, China
}

\begin{abstract}
Conversational interaction analysis is a method of analyzing the content and structure of the words spoken by both parties in a conversation. The listening discourse of TEM-8 has not only the basic characteristics of daily conversation discourse, but also its special features as a selective examination. This paper applies a combination of quantitative and qualitative methods, encompassing the perspectives of the construction and transformation of turn, the sequential organization of the conversation, and the repair of conversation, to carry out conversational interaction analysis on listening discourse materials of the TEM-8 in 2011, 2015 and 2019. The results revealed that candidates need to grasp the topic, match questions with answers, capture details, and pay attention to the role change, tone and repair of the conversation, as well as strengthen listening training, so that they can do well in TEM-8 exams.
\end{abstract}

Index Terms - test for English Majors-8, listening discourse, conversational interaction analysis

\section{INTRODUCTION}

Language communication in people's daily life includes oral communication and written communication. In oral communication, there are non-interactive methods such as monologues and speeches, as well as conversations that require both parties to participate. Conversational interaction analysis is a method of scientific analysis of people's conversational structure patterns in the course of interaction. The purpose is to find the basic rules of conversation from the recurring patterns in a large number of conversation records, and then dig deeper into conversations (Du, 2013).

The relevant papers which related to conversational interaction analysis include daily conversations (Wu \& Yang, 2020), classroom conversations (Zhang, 2019), and dialogue materials for large-scale oral exams such as CET-4, IELTS, and TOEFL (Gu, 2020), while not many papers focus on conversational interaction analysis on the listening discourse of the Test for English Majors-8 (TEM-8 for short). The listening discourse of TEM-8 doesn't only have the basic characteristics of daily conversation discourse, but also its special features as a selective examination. This article uses a combination of quantitative and qualitative methods, from the perspectives of the construction and transformation of turn, the sequential organization of the conversation, and the repair of the conversation, to analyze the listening discourse materials of TEM-8 in 2011, 2015 and 2019. It aims at finding some rules and characteristics of the conversational feature of the listening discourse of TEM-8, and giving some enlightenment to the candidate's listening comprehension.

\section{CONVERSATIONAL INTERACTION ANALYSIS}

The basic feature of conversation is interaction. There must be at least two participants in a conversation, and the speaker must complete social or communicative behaviors in an orderly manner. In the 1960s, the conversation analysis school represented by Sacks, Schegloff, and Jefferson proposed a method aimed at studying the internal structure of conversation. Conversation analysis is divided into two research orientations. The first one is theoretical conversation analysis. In theoretical conversation, only the conversation itself is studied, in which the composition, organizational structure, and conversation routines are analyzed, ignoring the social factors of the discourse. The second one is applied conversation analysis, whose purpose is to explore how conversational analysis theory is applied to various fields of our society. Paul Ten has called the former "Pure CA" and the latter "Applied CA". Conversational interaction analysis belongs to the category of "pure conversational analysis research". It is used to analyze the interactive characteristics of the two parties in the conversation and how the topic being discussed is regulated by the people engaged in the conversation. Its research focuses on conversation. The content includes three main aspects: (1) the construction and transformation of turn; (2) the sequential organization of conversation; (3) the repair of the conversation.

\section{A. Turn}

Foreign scholars Sacks, Schegloff and Jefferson (1978) believe that turn refers to a speaker continuously producing words during a conversation. When the roles of the speaker and the listener are exchanged or when both parties are silent, the speaker's turn is over. Liu Hong (2006), a domestic linguist, believes that turn refers to a series of words spoken by the speaker at any time during a conversation, ending with the exchange of speaker and listener or the silence of all people. This definition provides two measurable criteria for the end of a turn: first is the exchange of roles between the speaker and the listener, which marks the end of one turn and the beginning of the next. The second is 
whether the speaker's words are continuous. If the speaker is silent after uttering a word continuously in the conversation, and no other words are said later, it means that the current turn is finished.

\section{Turn-Construction}

The most basic unit of turn-construction is the turn-constructional unit (TCU). Turn-construction unit refers to the various language forms and components used to construct a turn. Generally, there are lexical-type TCU, phrase-type TCU and sentence-type TCU (Yan, 2018). A turn can be constructed by one or more turn-construction units. Turns have predictability, which means the parties involved in the conversation can infer the type of turn-construction unit and the possible ending point of the turn during the process of constructing. There are four turn-construction strategies: exploit resources and initiate the turn, unfold gradually and keep the turn, cope freely and change the turn, promote understanding and take turns (Zhou, 2011).

\section{a. Exploit Resources and Initiate the Turn}

To start a continuous conversation, not only a specific topic, discourse center, and resources for conversation are needed, but also the active participation of both sides (Sun, 2018). These conditions make it possible to keep the speakers talking and avoid silence caused by lack of topics or conversation resources, leading to the interruption of the conversation. Therefore, the first task of constructing a turn is to find suitable conversation resources for both parties to promote the natural generation of turn.

\section{Example 1}

W: Good morning, Dr. Harley. Thank you very much for coming on our radio talk. We know that you are an applied linguistic specializing in second language acquisition.

M: Right.

(Part 1 in Listening Comprehension Section B Interview of TEM-8, 2011)

In this material, interviewer W started the first turn with his greeting "Good morning". Then according to "We know that you are an applied linguistic specializing in second language acquisition", it's obvious that interviewee M's profession is mentioned as the topic of this turn, which build the foundation for further development of the conversation.

\section{b. Unfold Gradually and Keep the Turn}

After the turn is triggered, both parties in the conversation need to expand the turn around the topic, and some new questions can also be involved. If the speaker wants to keep the conversation from being interrupted in communication, he should learn to control the initiative of discourse effectively. Take the listening discourse material of TEM-8 in 2011 as an example. There are 22 turns in this material, during which the interviewer and the interviewee take turns to initiate the turn.

\section{Example 2}

$\mathrm{W}$ : So, age plays an important role in language learning?

M: Yes. But that's not the only reason.

$\mathrm{W}: \mathrm{Oh}$, is that so?

M: Yes. For example, time and interest. Old children and adults often have less time and motivation to learn a second language.

...

M: Well, this may be one of the issues here. But this cannot be the whole story. As not all differences between languages cause difficulty. Let me give you an example.

W: OK.

M: Research has found that many errors by Czech speakers learning English were made on syntactic constructions in which the two languages do not differ.

(Part 1 in Listening Comprehension Section B Interview of TEM-8, 2011)

There are two sentences in the turn of interviewee $\mathrm{M}$ in the material, "But that's not the only reason" and "Let me give you an example". These two sentences are at the end of what the interviewee M said, so it ought to the interviewer W's turn to speak after M's speaking. However, owing to these two sentences, the initiative of the turn still belongs to M. These sentences give him the opportunity to express more opinions.

\section{c. Cope Freely and Change the Turn}

During a conversation, it's a common communication obstacle in dialogue that there is silence between both parties from time to time. If they want to break the deadlock and maintain the conversation, the key is to initiate a new turn. After getting a new turn, it is necessary for both parties to be good at taking turns in the communication so that they will not fall into silence again. Thus, both parties should be able to explore new topics in order to start a new turn.

\section{d. Promote Understanding and Take Turns}

The effective continuation of the conversation depends on two speakers' accurate understanding of the content in the 
conversation. It is difficult for the conversation which is not comprehended by the listener to have the possibility of continuity. Therefore, during a conversation, the speaker can use explanations, repetitions and other strategies to ensure that the listener can understand his words. At the same time, the listener can also use some strategies such as asking, questioning, and supplementing to express his opinions based on their conversation. Finally, both parties can understand the meaning of the conversation in time, so as to promote the normal progress of the conversation.

\section{Turn-Taking}

When the speaker stops speaking and the listener starts to speak, the roles of both sides in the conversation are reversed, resulting in the change of a turn. The position where the roles change is called "turn-turn related position". The position associated with turn-taking is generally located at the end of a turn, and it usually changes in five aspects: intonation, phonetics, syntax, semantics and sign language (Duncan \& Niederehe, 1974). Based on this, Sacks, Schegloff and Jefferson proposed the concept of turn-taking in 1978. Sacks pointed out that the seemingly disorderly dialogue in daily life is actually a highly organized and orderly phenomenon. The hidden rules in the conversation that control the orderly progress of the conversation are called turn-taking mechanisms. People need to follow the basic principles in the communication process even though there is only one speaker. Based on the above analysis, the speakers in the conversation may infer a possible ending point of turn transformation, at which the transformation is most likely to occur. This point is called "transition-relevance place". The suitable points of turn-taking have five characteristics: completion of a complete grammatical sequence, appearance of summary utterances, reduction of intonation and volume, signals of the speaker's initiative to give up the turn by asking questions to others, and a long pause or silence (Gao, 2018).

Turn-taking is often used in oral communication teaching. Common types of turn-taking include modified turn-taking, induced turn-taking, insertion-type turn-taking, and distributed turn-taking (Zhang, 2019). In the process of teacher-student interaction in oral teaching, students' responses often appear inaccurate or inappropriate. At this time, teachers can use modified turn-taking to help students adjust their speech expressions and correct mistakes. Induced turn-taking is the most important way of turn-taking in oral communication. There are usually two types: direct inducement and indirect inducement. They are based on the original expression of the speaker and use some introductory sentences to link the dialogue so as to promote the next turn. When teachers and students communicate around a certain topic, many subtopics may be derived. If students are talking about the subtopics or any other unrelated topic, the teacher may interrupt the students' speech through insertion-type turn-taking, so that the students' attention can return to the main topic. Distributive turn-taking means that the teacher takes the initiative to specify the speaker for the next turn. Common methods include directly designating students to answer and guiding students to answer in a certain order.

\section{B. Sequential Organization}

The most prominent feature between turns in conversation is "adjacency". The generation of each turn shows the understanding of the speaker on previous turn. At the same time, the current turn also creates a new context for the generation of next turn. As a result, the sequence of conversation analysis is jointly constructed by the speakers. The behaviors performed by both sides are not only shown through the turn design, but also understood by the sequence position of the turn. This section discusses the global structure of a conversation called sequential organization, including three aspects: adjacency pairs, preference organization, and non-preference organization.

\section{Adjacency Pairs}

The concept of adjacency pairs was originally proposed by Schegloff and Sacks. Adjacency pairs are the concrete manifestation of the organization, language stability and repeatability of human social behaviors in conversation. The typical adjacency pairs are composed of two parts. The part that appears in the front usually represents the initiation of the utterance, which is called the antecedent of the adjacency pairs. While the part that appears in the back usually represents the response of the utterance, which is called the subsequent part of the adjacency pairs. Generally speaking, the antecedent and the subsequent parts of adjacency pairs are contributed by two speakers, which are adjacent to each other to form a system. And it is generally required that the subsequent parts of adjacency pairs are constrained by the antecedent pieces, which makes the sequential organization of a conversation exhibits a certain degree of stability and detectability. Liu Hong (2006) summarized 15 types of adjacency pairs based on the characteristics of Chinese:

(1) compliments-compliments; (2)farewell-farewell; (3)call-answer; (4)ask-answer;

(5) apology-relief/blame; (6)wish-thanks/blessings/relief; (7)introduction-compliments/introduction;

(8) suggestions-agreement/prevarication/objection/question;(9)thanks-humility/thanks;

(10) statement-statement/supplement/affirmation/question/confirm/negative;

(11) offer--accept/decline/prevarication/questioning;

(12) accusation-apology/deny/excuses/acknowledgment/controversy/provocation;

(13) praise-humble / thanks / agree / praise;

(14) request-accept / postpone / prevarication / rejection / questioning;

(15) congratulations-thanks / humble / congratulations.

\section{Example 3}


W: ... I want that money to be actually in the schools, for the schools to decide how it should be spent...

M: OK, thank you very much, Theresa, for talking to us on the program.

W: Pleasure.

(Part 2 in Listening Comprehension Section B Interview of TEM-8, 2015)

\section{Example 4}

M: ... Can you remember how many big hurricanes there have been in this country over the last few years? I think evidence is all around us.

W: I don't think we have enough information to be honest. We've only been measuring these things for around two or three hundred years...

(Part 1 in Listening Comprehension Section B Interview of TEM-8, 2019)

In the listening discourse material of TEM-8 in 2015, when both sides of the conversation have finished their talking, interviewer $\mathrm{M}$ expresses his appreciation for interviewee W's enthusiastic introduction by saying "OK, thank you very much, Theresa, for talking to us on the program". And then the interviewee W uses "pleasure" in response to interviewer M's gratitude, which belongs to the adjacency pair of "thanks-humility". Similarly, in the listening material of 2019, the first person of the conversation says the sentence "I think evidence is all around us" to state his views, and then the second person gives "I don't think we have enough information to be honest" to show the opposite view immediately, which belongs to the adjacency pair of "statement-negative".

\section{Preference and Non-Preference Organization}

Preference organization, which is gradually improved nowadays, is one of the core concepts of conversational interaction analysis research proposed in the 1970s and 1980s. Some researchers believed that under a certain sequential organization structure, the response behavior invited by the communicative partner is a priority behavior, otherwise is a non-priority behavior. And the structural characteristics of the turn which are used to implement the priority or non-priority behavior are the so-called preference organization or non-preference organization. Therefore, it is known to us that people usually regard those conversation behaviors that are directly executed without delay as the priority behavior of a conversation, and define the conversational behaviors that are explained and delayed in execution as non-priority behaviors. We need to pay attention that "priority" and "non-priority" here do not refer to the speaker's personal desire or psychological tendency, but refer to a highly generalized and institutionalized way of speaking.

Preference organization and non-preference organization are often used as a conversational strategy to achieve a certain conversational effect. But actually, in conversational interaction analysis, they are often explained together with adjacency pairs. Take the "question-answer" adjacency pairs in listening discourse material of TEM-8 in 2011 as an example.

\section{Example 5}

W: OK. Most people think, including me, it is difficult to learn another language. What are the reasons? Why is it so?

M: Well, there are a number of reasons for this. Ah, first, there have been research studies. They have shown that some aspects of language learning, especially syntax, are more difficult beyond a certain age, say, after around 12 years of age...

(Part 1 in Listening Comprehension Section B Interview of TEM-8, 2011)

In this piece of material, the interviewer W asks the question "What are the reasons? Why is it so?", followed by the answer of the interviewee M. So it could be inferred that this dialogue belongs to the adjacency pair of "ask-answer". According to W's question, the content of M's answer should state directly what the specific reasons are and why these reasons occur. But in fact, the interviewee $\mathrm{M}$ answers "Well, there are a number of reasons for this" at first, and combines specific research proofs as examples to prove then. And he doesn't state the specific reasons in a direct way in his answers. Instead, he hides the answers in the process of narration, which requires the interviewer W to sum up the answers from the narratives by himself. Therefore, such kind of answers are not in line with the requirements of preference organization.

\section{Repair}

Repair is a "self-correction" mechanism of conversation. In other words, repair can help to correct the improper or wrong expressions during a conversation so as to solve the problems of listening, speaking, and understanding between both sides in a conversation. In daily communication, for various reasons, the speaker constantly modifies what he said to achieve a more accurate communication. At the same time, the listener also checks his understanding of those words by questioning, repeating and other methods. Both the speaker and the listener are not only repairing themselves, but also repairing each other.

The studies of conversation interaction analysis have shown that there are many forms of repair in conversations. Due to the initiation and the resolution of repair could be performed by different communicators, the kind of repair can be divided into the following four categories:

(1) self-initiated-self-repair; (2)self-initiated - other-repair;

(3) other-initiated — self-repair; (4)other-initiated — other-repair.

In the listening material of 2011, when talking about the factors that could have influence on language learning, the interviewee wants to express the meaning of "the more special the characteristics of a language are, the more difficult it 
is to acquire". But the expression seems to be a little bit absolute to some degree. In order to solve this problem, the parenthesis "relative to other language" is added into his expression, which is a repair of the scope of discourse. And later, when it comes to the summary of teaching methods, the interviewee uses "I mean, all depending on specific conditions" to supplement his content after summarizing the characteristics of those teaching methods, which is a supplementary repair to the meaning of discourse.

\section{RESEARCH Questions AND RESEARCH MethodS}

\section{A. Research Questions}

The following specific questions are raised on the base of the above theoretical background:

(1)What are the characteristics of turn in TEM-8 listening discourse? What is the sequential organization of the conversation? What are the characteristics of repair in conversation?

(2)What kind of enlightenment do the conversational features in TEM-8 listening discourse give on students' performances when doing listening comprehension?

\section{B. Research Methods}

In this paper, a combination of quantitative and qualitative methods is used. The conversational materials are from the part of the interview in the listening texts of TEM8 in 2011, 2015 and 2019. Based on the theory of conversational interaction analysis, this paper analyzes the interactive features of a conversation from the following three perspectives, namely, the construction and transformation of turn, the sequential organization of conversation and the repair of conversation.

\section{RESULTS AND DISCUSSION}

Most of the listening comprehension materials in TEM-8 come from daily speeches, news and dialogues. The types of questions in listening comprehension include objective multiple-choice questions and subjective blank-filling questions, which improves the reliability and validity of the test paper overall. In this process, candidates' ability to get the main idea, grasp the details and understand the implied meaning between lines is trained (Hu \& Ni, 2015). Besides, in listening comprehension part of TEM-8, the materials and questions are read together, while only the choices will be presented on the test paper. So candidates must take full advantage of time before listening to browse the answers quickly so that they can have a general impression of the structure of each question, and infer what they need to pay attention to based on the answers. And the requirements of prediction and shorthand also increase the difficulty of the test in an invisible way (Wang, 2018).Therefore, giving an in-depth analysis and discussion of the listening comprehension materials in TEM-8 from the perspective of conversational interaction analysis is of great value to explore the rules of conversation structures and contents in listening comprehension materials. What's more, it can provide some inspirations for candidates' listening comprehension.

\section{A. Grasp the Topic and Pay Attention to the Role Change of Conversation}

Table 1 demonstrates the total number of the turns in the listening discourse materials in TEM-8 in 2011, 2015 and 2019.

TABLE 1

THE FEATURES OF TURN

\begin{tabular}{lccc}
\hline & Features & 2011 & 2015 \\
\hline The Number of Turns & 22 & 16 & 17 \\
\hline The Number of Sentences/Words & $46 / 447$ & $31 / 653$ & $44 / 606$ \\
\hline The Number of Words in One Turn (Maximum) & 61 & 118 & 122 \\
\hline The Number of Words in One Turn (Minimum) & 1 & 1 & 4 \\
\hline
\end{tabular}

It can be inferred that the difficulty of listening comprehension part in TEM-8 is increasing year by year. The number of turns in these three listening materials is around 20, and the total number of words is increasing year by year, but the number of sentences varies greatly, which is caused by the length of the turn. The length of a turn can be as long as more than one hundred words or as short as one word. Generally speaking, the answers of these listening questions are hidden in the turns, but candidates are easily distracted by the long turns, and they may waste too much time to read the long questions in multiple-choice questions, resulting in the inability to answer the questions correctly. Therefore, when listening to materials, candidates should pay attention to the first turn, which often contains significant information such as the main topic of this material, the identity information of the first speaker, or the general attitude of one speaker. Then the candidates can exclude the choices that do not conform to the topic of materials from the multiple-choice questions, and mark the contents related to the identity information of the speaker to facilitate listening to the following key points.

Taking the first question of the Interview part in the listening discourse material of TEM- 8 in 2011 as an example. The question is "What is Dr. Harley?", and the four choices are: an applied linguistic; a social linguistic; a 
psychological linguistic; a neuron linguistic. It can be seen that the four choices are all descriptions of linguists, and the difference lies in the different majors. Therefore, candidates can infer that this question is to examine the identity of the character. After focusing on "linguistic", they should keep an eye on the majors of characters and pay attention to sentences containing phrases such as "specialize in" "major in" and other adjectives or clauses that modify linguistic.

TABLE 2

THE TYPES AND NUMBERS OF TURN-TAKING

\begin{tabular}{cccc}
\hline Types of Turn-taking & 2011 & 2015 & 2019 \\
\hline Modified Turn-taking & 2 & 1 & 2 \\
\hline Induced Turn-taking & 9 & 5 & 5 \\
\hline Inserted Turn-taking & 0 & 1 & 2 \\
\hline Distributed turn-taking & 0 & 0 & 0 \\
\hline
\end{tabular}

Table 2 shows the types and numbers of turn-taking in the listening discourse material of TEM-8 in 2011, 2015 and 2019. From the table, we can see that the types of induced turn-taking accounted for the majority in the past three years, since one of the main characteristics of interview conversations is that most conversations are initiated by interviewers with some questions. Therefore, in addition to grasping the main topics when listening to the materials, candidates should also pay attention to the questions raised by the interviewers, and take notes of the follow-up detailed inquiries, such as "Can you give us some examples". After listening to the question clearly, it is natural to pay attention to the answers of the interviewee, which is caused by the turn-taking - the exchange of roles between the two sides. More importantly, the position of turn-taking often implies that the answers to the questions will appear.

\section{B. Match Questions with Answers and Pay Attention to the Tone of the Conversation}

TABLE 3

THE FEATURES OF SEQUENTIAL STRUCTURES

\begin{tabular}{lccc}
\hline \multicolumn{1}{c}{ Features } & 2011 & 2015 & \\
\hline The Number of Turns & 22 & 16 & \\
\hline The Number of Adjacency Pairs & 9 & 7 \\
\hline $\begin{array}{l}\text { Preferred Organization/ Dispreferred } \\
\text { Organization }\end{array}$ & $7 / 2$ & $5 / 2$ \\
\hline The Number of Insertion Sequences & $3 / 5$ & 0 & 17 \\
\hline
\end{tabular}

Table 3 illustrates the features and numbers of sequential structures. Taking the listening material of 2015 as an example. There are 16 turns and 7 adjacency pairs in the conversation in this year. Among the seven adjacency pairs, there are five places meet the rules of preferred organization, while two places show the dispreferred organization, and the number of insertion sequence is one. By observing the whole table, it can be found that the total number of adjacency pairs in the interview has not changed much, but the number of conversations meeting the preferred organization is gradually decreasing, which shows that the two participants of the conversation are inclined to answer questions indirectly to each other. This change makes it difficult for the candidates to hear the answer directly from the conversation as before. On the contrary, it requires candidates to analyze the conversation comprehensively according to the tones and diction raised by the speakers, which has higher requirements for the candidate's comprehensive use of English. So it can widen the gap between different candidates to a certain extent effectively.

When answering such questions, candidates should first pay attention to the speaker's question, so as to have a preliminary judgment on the structure of the question. Then, candidates should pay attention to the first sentence that the listener says. Although it may not have a direct answer to the question, it often contains the listener's tone and attitude, which is the emotional basis for their subsequent answers. Besides, candidates should browse the details of the choices, exclude the choices that contain absolute words such as "all people" or "must", and compare the other details in the choices while taking notes. According to the marks, the candidate should listen to the speaker's follow-up detailed answer, extract and integrate the key information, and get the correct answer.

\section{Capture Details and Pay Attention to the Repair of the Conversation}

Table 4 shows the different types of repair and its number of occurrences in the interview in TEM-8 in 2011, 2015 and 2019. 
TABLE 4

THE FEATURES OF REPAIR

\begin{tabular}{ccccc}
\hline & Types of Repair & 2011 & 2015 & 2019 \\
\hline Interviewee & Self-initiated-Self-repair & 3 & 2 & 0 \\
& Other-initiated-Self-repair & 0 & 0 & 0 \\
& Other-initiated-Other-repair & 0 & 0 & 0 \\
& Self-initiated-Other-repair & 0 & 0 & 2 \\
\hline Interviewer & Self-initiated-Self-repair & 0 & 0 & 1 \\
& Other-initiated-Self-repair & 2 & 0 & 0 \\
& Other-initiated-Other-repair & 0 & 1 & 2 \\
\hline
\end{tabular}

According to the statistics in the table, the repair of conversation is very common in listening comprehension materials of TEM-8, and the highest frequency type is interviewees' self-repair. They will repair their language from time to time according to the needs of conversation, so that the content in the conversation can be accurately conveyed and understood. At the same time, with the help of the repair initiated by others, interviewees can confirm whether the meaning of their words is accurate through the interviewer's rhetorical question, questioning and repetition, so as to ensure that the conversation can continue.

In the interview in TEM-8, most of the interviewers and interviewees relied on self-repair strategies to restate the meaning of words, and a few of them use other people's repair strategies. As long as the repair is involved, it means that the person who is mastering the turn may change or supplement his words. For example, when words such as "in other words" and "that is to say" appear, it implies that the speaker will give further explanation of what he just said. Sentences like "some people think it's right, but I don't think so" suggest that the meaning of the speaker's following words will change greatly or be opposite completely, which is often the key point in the examination of multiple-choice questions. Therefore, candidates need to listen to the emergence of conversations' repair attentively.

\section{Keep an Eye on the Basics and Strengthen Listening Training}

The results of conversational interaction analysis of listening comprehension materials in TEM- 8 can play a certain role in training candidates' test-taking skills. However, candidates should still attach importance to basic English language learning and consolidate their language skills in daily life. In the aspect of strengthening listening training, firstly, candidates can do morning reading for half an hour every day to imitate the pronunciation and intonation of each character in the audio, so as to strengthen their speech recognition ability. Secondly, they can also listen to the listening materials from different occasions and read some original English newspapers and books in order to expand the background knowledge of western culture. Thirdly, for cultivating the ability of inference, prediction, and shorthand etc., candidates can spend some time in listening practice whose level is equal to the requirements of TEM- 8 regularly.

\section{CONCLUSION}

Most of conversations in listening comprehension materials of TEM-8 meet the requirements of adjacency pairs. The construction and change of turn also have obvious lexical signs. At the same time, the views and attitudes of both sides of the conversation can also be reflected in the repair of the conversation. The change of preferred and dispreferred action in the conversation is an important factor that can widen the attainment discrepancy between candidates. Therefore, candidates need to grasp the features of each conversation, use prediction, inference and other skills reasonably, and do more listening training consciously in order to improve the grade of TEM-8.

\section{REFERENCES}

[1] Du, J. B. (2013). Yu pian fen xi jiao cheng [Discourse Analysis] (1st ed.). Wuhan University Press.

[2] Duncan,S.\& G. Niederehe. (1974). On signaling that it's your turn to speak. Journal of Experimental Social Psychology, 24 (3):234-247.

[3] Gao, P. (2018). Cong hua lun zhuan huan jiao du jie xi jue se jian guan xi ji qi shen fen jian gou [The analysis of the relationship between roles and their identity construction from the perspective of turn-talking]. Su zhou хие уиап хие bao, 33(3), $77-80$.

[4] Gu, X. D. (2020). Liu ji, ya si, tuo fu kou yu kao shi xing shi yu ti xing dui kao guan he kao sheng hui hua te zheng de ying xiang [The influence of the form and question type of Cet-6, IELTS and TOEFL on the conversational characteristics of examiners and examinees]. Wai yu yu fan yi, 27(3), 2-7.

[5] Hu, X. D. \& Ni, R. (2015). Ying yu zhuan ye ba ji shi juan fen xi [Test paper analysis of TEM-8]. Yu wen xue kan (wai yu jiao уи jiaо хие), 41(7), 128-130.

[6] Liu, H. (2006). Hui hua jie gou fen xi [Analysis of Conversational Structure].Peking University Press.

[7] Sacks, H. \& EA, Schegloff. \& G, Jefferson. (1978). Simplest Syntactics for the Organization of Turn-taking for Conversation. Language, 33 (4): 7-55.

[8] Sun, Y. H. (2018). Hui hua fen xi yan jiu fang fa de xin te zheng ji qi ying xiang [New features and implications of conversational analysis research methods]. Wai yи xue kan, 17(6), 41-46. 
[9] Wang, Y. F. (2018). Ting li yu pian zhong hui hua jie gou de yu yong fen xi ji qi dui ying yu jiao xue de qi shi [Pragmatic analysis of conversational structures in listening discourse and its implications for English teaching]. Wen jiao zi liao, 62(30), 227-228.

[10] Wu, Y. X. \& Yang, Y. F. (2020). Han yu ri chang hui hua zhong xu lie jie shu yu "hao ba" de hui hua fen xi [The conversational analysis of sequence ending "All right" in Chinese daily conversation]. Yи yan xue yan jiu, 27(1), 19-31.

[11] Yan, X. X. (2018). Context analysis of TV talk shows from the perspective of conversation analysis theory [Unpublished doctoral dissertation]. Chengdu University of Technology.

[12] Zhang, J. (2019). Yu wen kou yu jiao ji jiao xue zhong de "hua lun zhuan huan" fen xi [The analysis of "turn-taking" in Chinese oral communication teaching]. Han zi wen hua, 35(17), 138-141.

[13] Zhou, H. Y. (2011). Ying yu dui hua jiao xue zhong de hua lun jian gou ce lue [The strategies about turn-construction in English conversation]. Jiao yи yan jiи уи ping lun (xiao хие jiaо уи jiaо хие), 19(5), 69-71.

Ziyue Tang was born in Chengdu, China in 1996. She received her bachelor's degree in pedagogy from Chengdu Normal University, China in 2019.

She is currently a postgraduate student in the School of Foreign Languages, Chongqing Normal University, Chongqing, China. Her research interests focus on English teaching in elementary and secondary schools. 